\title{
Hematological and Biochemical Markers of Iron Status in a Male, Young, Physically Active Population
}

\author{
Lázaro Alessandro Soares Nunes, ${ }^{1}$ Helena Zerlotti W. Grotto, ${ }^{2}$ \\ René Brenzikofer, ${ }^{3}$ and Denise Vaz Macedo ${ }^{4}$ \\ ${ }^{1}$ Faculty of Biomedical Sciences, Metrocamp College-IBMEC Group, 13035-270 Campinas, SP, Brazil \\ ${ }^{2}$ Department of Clinical Pathology, School of Medical Sciences, State University of Campinas, 13083-881 Campinas, SP, Brazil \\ ${ }^{3}$ Laboratory of Instrumentation for Biomechanics, Physical Education Institute, State University of Campinas, \\ 13083-851 Campinas, SP, Brazil \\ ${ }^{4}$ Laboratory of Exercise Biochemistry-LABEX, Biochemistry Department, Biology Institute, State University of Campinas, \\ 13083-970 Campinas, SP, Brazil
}

Correspondence should be addressed to Lázaro Alessandro Soares Nunes; lazaroalessandro@yahoo.com.br

Received 21 February 2014; Accepted 5 June 2014; Published 22 June 2014

Academic Editor: Patrizia Cardelli

Copyright ( 2014 Lázaro Alessandro Soares Nunes et al. This is an open access article distributed under the Creative Commons Attribution License, which permits unrestricted use, distribution, and reproduction in any medium, provided the original work is properly cited.

\begin{abstract}
The aim of this study was to establish reference intervals (RIs) for the hemogram and iron status biomarkers in a physically active population. The study population included male volunteers $(n=150)$ with an average age of $19 \pm 1$ years who had participated in a regular and controlled exercise program for four months. Blood samples were collected to determine hematological parameters using a Sysmex XE-5000 analyzer (Sysmex, Kobe, Japan). Iron, total iron-binding capacity (TIBC), transferrin saturation and ferritin, and high-sensitivity C-reactive protein (CRP) concentrations in serum samples were measured using commercial kits (Roche Diagnostics, GmbH, Mannheim, Germany) and a Roche/Hitachi 902 analyzer. The RIs were established using the Ref Val program 4.1b. The leucocyte count, TIBC, and CRP and ferritin concentrations exhibited higher RIs compared with those in a nonphysically active population. Thirty volunteers (outliers) were removed from the reference population due to blood abnormalities. Among the outliers, 46\% exhibited higher CRP concentrations and lower concentrations of iron and reticulocyte hemoglobin compared with the nonphysically active population $(P<0.001)$. Our results showed that it is important to establish RIs for certain laboratory parameters in a physically active population, especially for tests related to the inflammatory response and iron metabolism.
\end{abstract}

\section{Introduction}

The physical training undertaken by athletes results in different degrees of microtrauma to the muscle. This microtrauma is related to the acute inflammatory response, which promotes muscle repair and regeneration. This response involves the production, recruitment, and delivery of proteins (e.g. cytokines, immunoglobulins, and acute phase proteins) and cells (e.g., leukocytes) in the circulation [1]. Acute and chronic exercise training produce different effects on hematological parameters. After a single bout of exercise, there is a rapid and pronounced neutrophilia due to demargination caused by shear stress and catecholamines, followed by a second delayed increase due to the cortisol-induced release of neutrophils from the bone marrow $[2,3]$. Whereas the numbers of monocytes and lymphocytes can increase during and immediately after an exercise bout, the lymphocyte count falls below preexercise levels during the early stages of recovery, returning to basal levels within 4 hours [4]. All of these numbers generally return to basal levels within 3-24 hours [5].

Exercise training can influence immune function, health, and performance. In general, exercise training with lowto-moderate volume and intensity, with gradual increases, 
can enhance immune function and reduce the incidence of infections [3]. However, among highly trained and elite athletes, high-intensity training periods and strenuous physical exercise are associated with an increased susceptibility to upper respiratory tract infections (URTIs) $[3,6,7]$. Moreover, other factors, including lifestyle behaviors and nutritional status, can influence an athlete's immune function. Hence, monitoring an athlete's immune function through hematological parameters has become an important part of competition preparation [4].

Fully automated hematology analyzers have the capacity to quantify reticulocytes, the immature form of erythrocytes. The evaluation of immature red blood cell (RBC) parameters, including the number and hemoglobin content of reticulocytes, can be useful for monitoring positive adaptations to training or for identifying the use of prohibited substances to stimulate bone marrow production. Moreover, measuring hemoglobin concentration and reticulocyte parameters may be useful for diagnosing sports anemia, which can impair an athlete's performance. Persistent abnormalities in RBCs, hemoglobin concentration, and hematological indices can also indicate pathological conditions, such as deficits in iron, folic acid, or vitamin B12. Furthermore, other hematological abnormalities (thalassemia, sickle cell disease, and hereditary spherocytosis) can also alter an athlete's RBC profile $[8,9]$.

Athletic-induced iron deficiency is commonly detected in athletes, particularly those who engage in endurance sports. Iron is an essential component of hemoglobin, myoglobin, cytochromes, and other iron-containing proteins that participate in oxidative phosphorylation [10]. Additionally, macrophages can accumulate iron derived from RBCs, which is recycled by the reticuloendothelial system and thus participates in the immune defense against microbial pathogens [11]. In the bloodstream, iron is coupled to transferrin and can inhibit damage by reactive oxygen species (ROS) derived from Fenton's reaction [12]. In reticuloendothelial cells in the liver, spleen, and bone marrow, iron is stored as ferritin and hemosiderin [13].

To monitor immune function and iron status in athletes, it is important to understand the influence of exercise training on hematological and iron-related biochemical parameters. To increase the utility of these screening tests in physically active individuals, it is crucial to establish specific reference intervals in a physically active population, according to the International Federation of Clinical Chemistry (IFCC) rules. The aim of this study was to establish reference intervals for the hemogram, high-sensitivity C-reactive protein, and iron status biomarkers in young male individuals who had undergone 4 months of regular physical activity.

\section{Materials and Methods}

2.1. Participants. The study included five hundred $(n=150)$ healthy male volunteers with an average age of $19 \pm 1$ years. All the participants were in the first stage of physical and educational preparation for careers in the army. They were from different regions of the country, and, for one year, they had lived at the same place and had participated in the same numbers of hours of sleeping, eating, exercising, and studying. The volunteers participated in a regular and strictly controlled exercise program, which consisted predominantly of aerobic activities (high volume and different submaximal intensities), such as running and swimming. They had exercised three hours daily for four months in 2011 (from February to May). They had trained five days per week, with two days of rest. This group constituted a highly uniform group of young, physically active individuals. The participants provided written formal consent for participation in the research. The participants completed a questionnaire concerning their use of medication, complaints of pain, and injuries caused by training. Were selected for the reference group only those with no history of tobaccoism or chronic inflammatory disease. Those who were using medications, had not trained in the last three days, exhibited different clinical conditions (injuries related to training, muscle pain complaints, shin splint, or flu), or were suspected of congenital disorders (thalassemia or sickle cell disease) were analyzed separately as outliers. This study was approved by the University Ethics Committee for Research with Humans (CAAE: 0200.0.146.000-08). All the study procedures were in accordance with the Declaration of Helsinki.

2.2. Blood Sampling and Analysis. All blood samples were collected after two days of rest to avoid the effects of hemodynamic variations and acute hemodilution that are induced by exercise [14]. The blood samples were collected under the following standardized conditions: $2.0 \mathrm{~mL}$ of total venous blood was collected in vacuum tubes containing EDTA/K3 to determine hematological parameters, and $8.0 \mathrm{~mL}$ was collected in tubes with a Vacuette (Greiner Bio-one, Brazil) gel separator to obtain serum for biochemical measurements. The blood samples were collected in the morning after 12 hours of fasting, with the subjects being in a seated position. All the samples were then transported to the laboratory at $4^{\circ} \mathrm{C}$ and were analyzed within $60 \mathrm{~min}$ after the blood collection. The hematological parameters were obtained with a Sysmex XE-5000 automated analyzer, which uses a polymethine dye specific for RNA/DNA to facilitate reticulocyte enumeration and determinations of degree of immaturity and hemoglobin content. The e-Check (Lot 1144) Sysmex 3 levels were used as an internal quality control and were performed in parallel with the hematological tests. The means and standard deviation derived from the control samples were used to calculate the coefficient of analytical variation $\left(\mathrm{CV}_{A}\right)$. The analyzed parameters and each respective $\mathrm{CV}_{A}$ were as follows: red blood cell count $(\mathrm{RBC})\left(\mathrm{CV}_{A}=0.7 \%\right)$; blood hemoglobin concentration $(\mathrm{Hb})\left(\mathrm{CV}_{A}=1.1 \%\right)$; hematocrit $(\mathrm{Ht})\left(\mathrm{CV}_{A}=\right.$ $1.0 \%)$; mean corpuscular volume $(\mathrm{MCV})\left(\mathrm{CV}_{A}=0.8 \%\right)$; erythrocyte distribution width (RDW) $\left(\mathrm{CV}_{A}=0.9 \%\right)$; mean corpuscular hemoglobin $(\mathrm{MCH})\left(\mathrm{CV}_{A}=1.0 \%\right)$; mean corpuscular hemoglobin concentration $(\mathrm{MCHC})\left(\mathrm{CV}_{A}=\right.$ $1.2 \%)$; reticulocyte count (Ret) $\left(\mathrm{CV}_{A}=3.7 \%\right)$; immature reticulocyte fraction (IRF) $\left(\mathrm{CV}_{A}=10.0 \%\right)$; reticulocyte hemoglobin equivalent (Ret-He) $\left(\mathrm{CV}_{A}=2.5 \%\right)$; white blood cell (WBC) $\left(\mathrm{CV}_{A}=2.2 \%\right)$, lymphocyte (Lymph) $\left(\mathrm{CV}_{A}=2.3 \%\right)$, neutrophil (Neut) $\left(\mathrm{CV}_{A}=3.0 \%\right)$, monocyte 
TABLE 1: The reference intervals, confidence intervals, and outliers excluded by Horn's algorithm for hematological parameters in a male, young, physically active population.

\begin{tabular}{|c|c|c|c|c|c|}
\hline \multirow{2}{*}{ Analyses } & \multirow{2}{*}{$\begin{array}{c}\text { Reference interval } \\
2.5 \text { th-97.5th }\end{array}$} & \multicolumn{2}{|c|}{$90 \%$ confidence interval } & \multirow{2}{*}{ Subjects $(n)$} & \multirow{2}{*}{ Outliers $(n)$} \\
\hline & & 2.5th & 97.5th & & \\
\hline $\mathrm{WBC}\left(10^{9} / \mathrm{L}\right)$ & $5.0-10.8$ & $4.9-5.2$ & $10.4-11.7$ & 119 & 1 \\
\hline Lymph (\%) & $15.0-48.0$ & $14.0-19.0$ & $43-53$ & 119 & 1 \\
\hline Lymph $\left(10^{9} / \mathrm{L}\right)$ & $1.3-3.7$ & $1.2-1.4$ & $3.3-4.1$ & 119 & 1 \\
\hline Neut (\%) & $37.0-72.0$ & $33.0-41.0$ & $67.0-76.0$ & 120 & - \\
\hline Neut $\left(10^{9} / \mathrm{L}\right)$ & $2.4-7.5$ & $2.3-2.5$ & $6.6-8.0$ & 119 & 1 \\
\hline Mono (\%) & 7. $0-13.0$ & $6.5-7.5$ & $13.0-15.0$ & 118 & 2 \\
\hline Mono $\left(10^{9} / \mathrm{L}\right)$ & $0.4-1.4$ & $0.3-0.5$ & $1.1-1.5$ & 118 & 2 \\
\hline Eo $(\%)$ & $0.9-7.7$ & $0.8-1.2$ & $7.0-7.8$ & 114 & 6 \\
\hline Eo $\left(10^{9} / \mathrm{L}\right)$ & $0.05-0.55$ & $0.04-0.08$ & $0.53-0.87$ & 118 & 2 \\
\hline Baso (\%) & $0.4-1.8$ & $0.3-0.4$ & $1.5-1.9$ & 117 & 3 \\
\hline Baso $\left(10^{9} / \mathrm{L}\right)$ & $0.02-0.11$ & $0.01-0.03$ & $0.11-0.15$ & 120 & - \\
\hline $\operatorname{PLT}\left(10^{9} / \mathrm{L}\right)$ & $141-305$ & $133-153$ & $284-320$ & 120 & - \\
\hline MPV (fL) & $9.8-13.4$ & $9.7-10.1$ & $13.0-13.7$ & 120 & - \\
\hline IPF (\%) & $2.0-10.4$ & $1.7-2.2$ & $9.9-11.8$ & 119 & 1 \\
\hline $\mathrm{RBC}\left(10^{12} / \mathrm{L}\right)$ & $4.77-5.72$ & $4.74-4.84$ & $5.57-5.77$ & 118 & 2 \\
\hline $\mathrm{Ht}(\%)$ & $40.6-47.4$ & $39.4-41.0$ & $46.6-48.9$ & 120 & - \\
\hline $\mathrm{Hb}(\mathrm{g} / \mathrm{L})$ & $133-162$ & $132-135$ & $158-163$ & 118 & 2 \\
\hline MCV (fL) & $80.0-89.5$ & $79.5-80.7$ & $88.6-91.2$ & 118 & 2 \\
\hline $\mathrm{MCH}(\mathrm{pg})$ & $26-30.0$ & 24-26 & 30-31 & 120 & - \\
\hline $\mathrm{MCHC}(\mathrm{g} / \mathrm{L})$ & $32-35$ & $31-32$ & $34-35$ & 119 & 1 \\
\hline RDW (\%) & $12.4-14.9$ & $12.4-12.7$ & $14.7-15.2$ & 119 & 1 \\
\hline RDW-SD (fL) & $38-45$ & $37-38$ & $44-46$ & 120 & - \\
\hline RET (\%) & $0.54-1.33$ & $0.5-0.6$ & $1.2-1.4$ & 120 & - \\
\hline $\operatorname{RET}\left(10^{9} / \mathrm{L}\right)$ & 28-68 & $24-30$ & $64-75$ & 120 & - \\
\hline IRF (\%) & $3-14$ & $2.7-3.6$ & $11.5-15.0$ & 119 & 1 \\
\hline Ret-He (pg) & $32.2-39.2$ & $31.6-33.0$ & $38.5-39.4$ & 119 & 1 \\
\hline
\end{tabular}

(Mono) $\left(\mathrm{CV}_{A}=6.2 \%\right)$, basophil (Baso) $\left(\mathrm{CV}_{A}=2.5 \%\right)$, eosinophil (Eo) $\left(\mathrm{CV}_{A}=7.5 \%\right)$; platelet $(\mathrm{PLT})$ counts $\left(\mathrm{CV}_{A}=\right.$ $2.6 \%)$; mean platelet volume (MPV) $\left(\mathrm{CV}_{A}=1.0 \%\right)$; and immature platelet fraction (IPF) $\left(\mathrm{CV}_{A}=5.6 \%\right)$. The biochemical measurements were conducted using commercial kits (Roche Diagnostics, GmbH, Mannheim, Germany) and a Roche/Hitachi 902 analyzer. Control serum was used to estimate the imprecision of the methods of biochemical analysis. The assays included the serum concentrations of iron $\left(\mathrm{CV}_{A}=1.0 \%\right)$, ferritin $\left(\mathrm{CV}_{\mathrm{A}}=2.1 \%\right)$, and highsensitivity C-reactive protein (h-CRP) $\left(\mathrm{CV}_{A}=3.2 \%\right)$ as well as total iron-binding capacity (TIBC) $\left(\mathrm{CV}_{A}=5.4 \%\right)$. The percent transferrin saturation (\% TSAT) was calculated as follows: $[\mathrm{iron} /(\mathrm{TIBC})] \times 100$.

2.3. Statistical Analysis. The data were tested for Gaussian distribution using the Kolmogorov-Smirnov test. The MannWhitney test for nonparametric distribution was used to determine the differences between the high h-CRP (outliers) and normal h-CRP (reference individuals) groups. GraphPad Prism 6.0 for Mac OS X (GraphPad Software) was used to perform the statistical analyses and create the graphs. Values of $P<0.05$ were considered significant. Reference intervals were established according to the IFCC rules using RefVal program 4.1 beta [15]. We calculated the nonparametric 2.5 th and 97.5 th percentiles, with their $90 \%$ confidence intervals (CIs), using a bootstrap methodology. Horn's algorithm was used to remove the outliers from the reference population [16].

\section{Results}

After the blood sample analyses, 22 individuals who exhibited abnormal blood results (leukocyte count $>12.0 \times 10^{9} / \mathrm{L}$, hemoglobin concentration $<120 \mathrm{~g} / \mathrm{L}$, or C-reactive protein level $>15.0 \mathrm{mg} / \mathrm{L})[17,18]$ or different clinical conditions (injuries related to training, muscle pain complaints, shin splint, or flu) were classified as outliers and were removed from the reference interval calculation. Additionally, eight individuals with mild microcytosis and higher RBC numbers, which are characteristics of thalassemia, were identified using the Mentzer index [19] and were excluded from the reference population and also included as outliers. As such, 120 healthy, physically active individuals constituted the reference sample group (Table 1). 
TABLE 2: The reference intervals, confidence intervals, and outliers excluded by Horn's algorithm for biochemical parameters in a male, young, physically active population.

\begin{tabular}{|c|c|c|c|c|c|}
\hline \multirow{2}{*}{ Analyses } & \multirow{2}{*}{$\begin{array}{c}\text { Reference interval } \\
2.5 \text { th-97.5th }\end{array}$} & \multicolumn{2}{|c|}{$90 \%$ confidence interval } & \multirow{2}{*}{ Subjects $(n)$} & \multirow{2}{*}{ Outliers $(n)$} \\
\hline & & 2.5 th & 97.5th & & \\
\hline h-CRP (mg/L) & $0.2-10.2$ & $0.2-0.3$ & $7.0-14.8$ & 120 & - \\
\hline Iron $(\mu \mathrm{mol} / \mathrm{L})$ & $8.4-28.8$ & $8.2-8.9$ & $27.5-31.6$ & 119 & 1 \\
\hline TIBC $(\mu \mathrm{mol} / \mathrm{L})$ & $43.8-64.5$ & $43.1-45.0$ & $63.1-68.9$ & 120 & - \\
\hline$\% \mathrm{TSAT}$ & $19-45$ & $19-20$ & $43-46$ & 119 & 1 \\
\hline Ferritin $(\mu \mathrm{g} / \mathrm{L})$ & $47-331$ & $41-53$ & $264-436$ & 119 & 1 \\
\hline
\end{tabular}

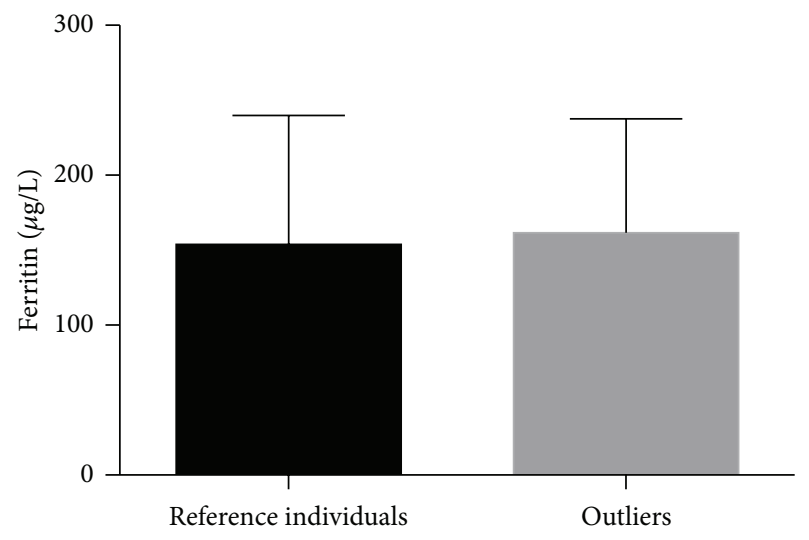

(a)

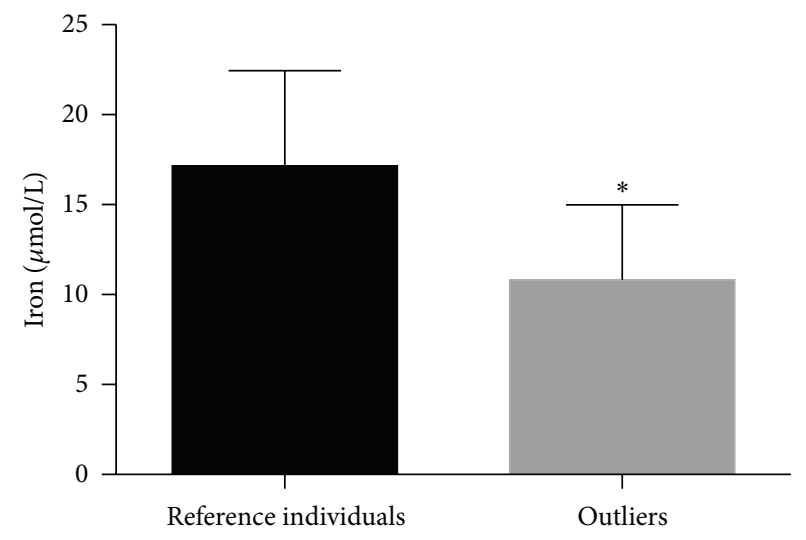

(b)

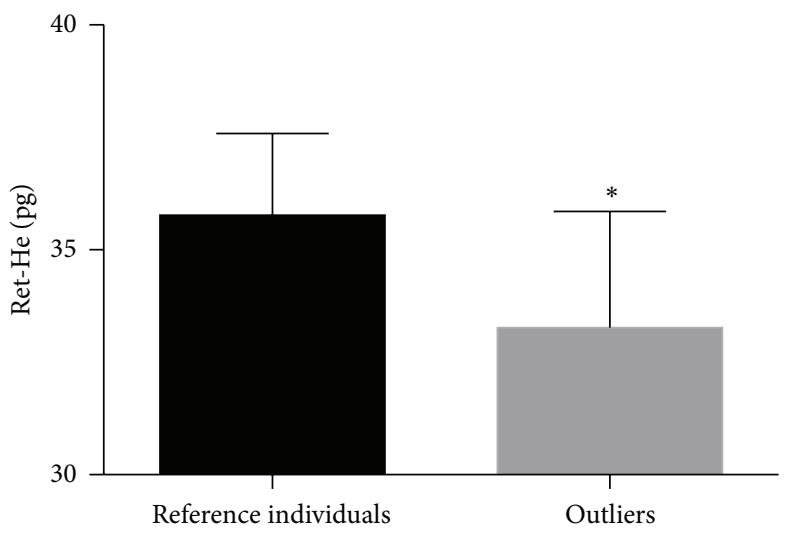

(c)

FIGURE 1: Ferritin (a), iron (b), and Ret-He (c) values in reference individuals (normal h-CRP) $(n=119)$ compared with outliers (higher h-CRP) $(n=14)$. The normal CRP reference range $(<10.2 \mathrm{mg} / \mathrm{L})$ was based on a reference population study. The graph shows the means \pm standard deviation. ${ }^{*} P<0.001$.

Table 1 shows the reference intervals $(2.5$ th and 97.5 th percentiles) and the respective confidence intervals for the examined hematological parameters in male, young, physically active individuals after four months of regular and systematized training. The outliers detected by Horn's algorithm (indicated in Table 1) were removed from the reference interval calculation.

Table 2 shows the reference intervals and confidence intervals for iron status and acute phase proteins in male, young, physically active individuals.

In this study, 30 subjects were classified as outliers due to abnormal blood results and were excluded from the reference interval calculation. Moreover, 46\% $(n=14)$ of the subjects classified as outliers presented CRP values above the reference intervals for physically active subjects. Figure 1 shows a comparison of the ferritin (a), iron (b), and Ret-He (c) values between the reference individuals (normal CRP concentrations) and outliers (higher CRP concentrations).

No differences in ferritin levels were observed between the normal and higher CRP groups (Figure 1(a)). The iron (Figure 1(b)) and Ret-He (Figure 1(c)) values were significantly lower in the higher CRP group compared with the reference group $(P<0.001)$. 


\section{Discussion}

Previous studies from our group showed that different young, physically active individuals respond to four months of training stimulus similarly to athletes in terms of certain parameters in blood [17] and saliva [20], justifying the use of this young male trained population to establish reference intervals for sports medicine applications.

Exercise training appears to result in local and systemic imbalances in the anti-inflammatory, compared with the proinflammatory, status. This imbalance promotes tissue adaptation and protects the organism against the development of chronic inflammatory diseases and against the deleterious effects of overtraining, a condition in which systemic and chronic proinflammatory and prooxidant states appear to preponderate $[21,22]$. In our population, we found slightly higher WBC and neutrophil counts in the lower percentile compared with healthy sedentary individuals $(\mathrm{WBC}=3.5-$ $9.8 \times 10^{9} / \mathrm{L}$ and Neut $\left.=1.5-7.0 \times 10^{9} / \mathrm{L}\right)[23]$. The 2.5th and 97.5th percentile monocyte counts (Table 1) were higher than those of a healthy, nonphysically active population (Mono = $0.2-0.64 \times 10^{9} / \mathrm{L}$ ) [23], indicating the effects of training on this parameter. Blood monocytes are the main source of tissue macrophages recruited in response to exercise [24], and they participate in the repair, growth, and regeneration of muscles [25].

There is little published evidence suggesting clinical differences between the immune functions of sedentary and physically active subjects in the true resting state (i.e., more than $24 \mathrm{~h}$ after the last training session) [1]. In our study of physically active subjects, we found a slightly higher lymphocyte count compared with a nonphysically active population (lymphocytes $=1.0-2.9 \times 10^{9} / \mathrm{L}$ ) [23] .

The reference intervals for RBC parameters determined in our study did not differ from those in a nonphysically active population [23]. In sports medicine, mature and immature erythrocytes can be assessed to identify possible doping methods, such as the enhancement of oxygen transport by recombinant erythropoietin (rEPO) abuse. This indirect form of doping control was implemented by the World Anti-Doping Agency (WADA) through the hematological module of the athlete biological passport (ABP). As a part of the ABP, assessments of hemoglobin concentration and reticulocyte count allow the estimation of oxygen blood transport capacity and recent RBC production, respectively [26]. The reference intervals for reticulocyte count obtained in our study of physically active individuals were similar to those for a healthy nonphysically active population [23] and for athletes, including cyclists, swimmers, rugby players, tennis players, and soccer players [27-29].

The IRF in our population was relatively high compared with the general population (1.6-10.5\%) using the same hematology analyzer [23]. The continuous stimulation of bone marrow due to accelerated iron metabolism, hypoxia, and exercise-induced hemolysis in athletes can partially explain this difference $[8,30]$. Moreover, IRF can be a sensitive marker of erythropoietic activity in athletes undergoing altitude training or exposed to exogenous EPO stimuli [28].
Acute exercise bouts have been shown to promote an acute phase response, resulting in postexercise cytokine levels similar to those observed during sepsis or inflammatory disease. Strenuous exercise induces moderate increase in proinflammatory cytokines tumor necrosis factor $\alpha$ (TNF- $\alpha$ ) and interleukin $1 \beta$ [21, 31]. Interleukin-6 (IL-6) derived from the muscle cells can rise up to 100 -fold during the exercise compared to preexercise levels [21]. CRP is the major acute phase protein associated with coronary events in apparently healthy subjects. Our CRP reference interval for physically active individuals (Table 2) was based on the 97.5th percentile. Other studies have found similar results for the 95th percentile in healthy, nonphysically active populations [32-34]. However, it is important to emphasize that these values are above the value $(>3.0 \mathrm{mg} / \mathrm{L})$ used to determine groups at high risk of cardiovascular disease, which is based on CRP [34]. Interleukin-6, which is produced in response to continuous training, can stimulate the synthesis of acute phase proteins by hepatocytes and can promote an elevated steady-state CRP concentration compared with healthy, nonphysically active subjects.

Iron, TIBC, and ferritin levels are traditional biomarkers for screening athletes during the training season [35]. Iron deficiency may have a negative impact on oxygen transport and immune defense, thus influencing athletic performance [36]. The main mechanisms of exercise-related iron loss in athletes include hemolysis, hematuria, sweating, gastrointestinal bleeding, and chronic inflammation [36]. Iron metabolism must be tightly regulated to supply iron as needed while avoiding the toxicity associated with iron excess. The main stimuli to regulate iron homeostasis are hypoxia, iron deficit, iron overload, and inflammation. In addition, iron metabolism is influenced by nutritional status, age, gender, bone marrow activity, and some pathological conditions such as bacterial infections [37]. Furthermore, recent reports have suggested that hepcidin, an iron-regulatory peptide hormone mainly produced in the liver, can regulate plasma iron concentrations in response to inflammation [38]. Hepcidin regulates iron concentration and tissue iron distribution via the inhibition of intestinal absorption, released by macrophages and iron mobilization from hepatic stores [39]. The primary mediator for the upregulation of hepcidin is IL6 [40, 41]. Hepcidin levels increase 3-24 hours after exercise in response to IL-6, producing rapid decreases in the plasma iron concentration [40,41]. The hepcidin synthesis decreases in iron deficiency, anaemia, and hypoxia [37]. The two last conditions are associated with increased erythropoiesis secondary to a rise of EPO secretion [42].

In our study, some subjects were classified as outliers due to high CRP concentrations and were excluded from the reference interval calculation. They had lower iron and hemoglobin reticulocyte concentrations (Ret-He), similar to those found in individuals with anemia of chronic disease (ACD). ACD results from the activation of the immune and inflammatory systems, resulting in the increased production of inflammatory cytokines that reduce the rate of iron mobilization from tissue stores [43]. The degree of hemoglobinization in reticulocytes is used to detect functional iron deficits and enables the early evaluation of bone marrow activity [44]. 
Ferritin levels, a biomarker of iron stores, did not differ between the higher and normal CRP groups (Figure 1(a)). Ferritin is an acute phase protein that is upregulated by tumor necrosis factor $\alpha$ (TNF- $\alpha$ ) and interleukin 2 (IL-2), two proinflammatory cytokines produced during and after strenuous exercise $[3,45]$. It is possible that the chronic inflammation state present in these subjects masked the changes in plasma ferritin levels. Although the results indicate a link between chronic inflammation and iron status parameters in these individuals, one limitation of this study was the lack of blood sample collection before the exercise program to identify the possibility of a prior inflammatory state. Thus, our comparisons were based on prior published studies conducted under specific conditions using different instruments. This limitation is particularly relevant for several parameters, such as monocytes, IRF, and reticulocytes [23]. Future investigations could verify this association in a larger sample including TNF- $\alpha$, IL-2, and IL-6 results.

\section{Conclusions}

In conclusion, our results showed that it is important to consider exercise training when establishing reference intervals for several specific parameters, mainly those related to the inflammatory response. In addition, to avoid deficits in iron, an element that is crucial for an athlete's performance, it is important to monitor iron status using new hematological parameters and inflammatory biomarkers.

\section{Conflict of Interests}

The authors declare that there is no conflict of interests regarding the publication of this paper.

\section{Acknowledgments}

The authors gratefully acknowledge the volunteers who participated in this study, Gisélia Aparecida Freire Maia de Lima, Maria de Fátima Gilberti (PhD), Flaviani Papaleo (MD), and Fernanda L. Lazarim (PhD), for their assessment of the research methodology. The biochemical and hematological quantification kits required for this study were generously provided by Sysmex and Roche do Brasil. LASN received a scholarship from Extecamp (927.7/0100).

\section{References}

[1] N. P. Walsh, M. Gleeson, R. J. Shephard et al., "Position statement part one: immune function and exercise," Exercise Immunology Review, vol. 17, pp. 6-63, 2011.

[2] D. A. McCarthy, I. Macdonald, M. Grant et al., "Studies on the immediate and delayed leucocytosis elicited by brief (30-min) strenuous exercise," European Journal of Applied Physiology and Occupational Physiology, vol. 64, no. 6, pp. 513-517, 1992.

[3] M. Gleeson, "Immune function in sport and exercise," Journal of Applied Physiology, vol. 103, no. 2, pp. 693-699, 2007.

[4] M. W. Kakanis, J. Peake, E. W. Brenu et al., “The open window of susceptibility to infection after acute exercise in healthy young male elite athletes," Exercise Immunology Review, vol. 16, pp. 119-137, 2010.

[5] M. Gleeson, "Can nutrition limit exercise-induced immunodepression?” Nutrition Reviews, vol. 64, no. 3, pp. 119-131, 2006.

[6] C. Malm, "Susceptibility to infections in elite athletes: the Scurve," Scandinavian Journal of Medicine and Science in Sports, vol. 16, no. 1, pp. 4-6, 2006.

[7] S. Bermon, "Airway inflammation and upper respiratory tract infection in athletes: is there a link?" Exercise Immunology Review, vol. 13, pp. 6-14, 2007.

[8] R. D. Telford, G. J. Sly, A. G. Hahn, R. B. Cunningham, C. Bryant, and J. A. Smith, "Footstrike is the major cause of hemolysis during running," Journal of Applied Physiology, vol. 94, no. 1, pp. 38-42, 2003.

[9] K. W. Mercer and J. J. Densmore, "Hematologic disorders in the athlete," Clinics in Sports Medicine, vol. 24, no. 3, pp. 599-621, 2005.

[10] Y. Olaf Schumacher, A. Schmid, D. Grathwohl, D. Bültermann, and A. Berg, "Hematological indices and iron status in athletes of various sports and performances," Medicine and Science in Sports and Exercise, vol. 34, no. 5, pp. 869-875, 2002.

[11] S. Recalcati, M. Locati, E. Gammella, P. Invernizzi, and G. Cairo, "Iron levels in polarized macrophages: regulation of immunity and autoimmunity, Autoimmunity Reviews, vol. 11, no. 12, pp. 883-889, 2012.

[12] J. Finaud, G. Lac, and E. Filaire, "Oxidative stress: relationship with exercise and training," Sports Medicine, vol. 36, no. 4, pp. 327-358, 2006.

[13] R. Hinzmann, "Iron metabolism. From diagnosis to treatment and monitoring," Sysmex Journal International, vol. 13, no. 2, pp. 65-74, 2004.

[14] M. N. Sawka, V. A. Convertino, E. R. Eichner, S. M. Schnieder, and A. J. Young, "Blood volume: importance and adaptations to exercise training, environmental stresses, and trauma/sickness," Medicine and Science in Sports and Exercise, vol. 32, no. 2, pp. 332-348, 2000.

[15] H. E. Solberg, "The IFCC recommendation on estimation of reference intervals. The RefVal program," Clinical Chemistry and Laboratory Medicine, vol. 42, no. 7, pp. 710-714, 2004.

[16] P. S. Horn, L. Feng, Y. Li, and A. J. Pesce, "Effect of outliers and nonhealthy individuals on reference interval estimation," Clinical Chemistry, vol. 47, no. 12, pp. 2137-2145, 2001.

[17] L. A. S. Nunes, R. Brenzikofer, and D. V. Macedo, "Reference change values of blood analytes from physically active subjects," European Journal of Applied Physiology, vol. 110, no. 1, pp. 191198, 2010.

[18] L. A. S. Nunes, F. L. Lazarim, F. Papaléo, R. Hohl, R. Brenzikofer, and D. V. Macedo, "Muscle damage and inflammatory biomarkers reference intervals from physically active population," Clinical Chemistry, vol. 57, supplement 10, p. A35, 2011.

[19] W. C. Mentzer Jr., "Differentiation of iron deficiency from thalassaemia trait," The Lancet, vol. 1, no. 7808, pp. 882-884, 1973.

[20] L. A. S. Nunes, R. Brenzikofer, and D. V. Macedo, "Reference intervals for saliva analytes collected by a standardized method in a physically active population," Clinical Biochemistry, vol. 44, no. 17-18, pp. 1440-1444, 2011.

[21] A. M. W. Petersen and B. K. Pedersen, "The anti-inflammatory effect of exercise," Journal of Applied Physiology, vol. 98, no. 4, pp. 1154-1162, 2005. 
[22] M. Gleeson, N. C. Bishop, D. J. Stensel, M. R. Lindley, S. S. Mastana, and M. A. Nimmo, "The anti-inflammatory effects of exercise: mechanisms and implications for the prevention and treatment of disease," Nature Reviews Immunology, vol. 11, no. 9, pp. 607-610, 2011.

[23] J. Van den Bossche, K. Devreese, R. Malfait et al., "Reference intervals for a complete blood court determined on different automated haematology analysers: Abx Pentra 120 retic, Coulter Gen-S, Sysmex SE 9500, Abbott Cell Dyn 4000 and Bayer Advia 120," Clinical Chemistry and Laboratory Medicine, vol. 40, no. 1, pp. 69-73, 2002.

[24] S. Gordon and F. O. Martinez, "Alternative activation of macrophages: mechanism and functions," Immunity, vol. 32, no. 5, pp. 593-604, 2010.

[25] J. G. Tidball and M. Wehling-Henricks, "Macrophages promote muscle membrane repair and muscle fibre growth and regeneration during modified muscle loading in mice in vivo," The Journal of Physiology, vol. 578, no. 1, pp. 327-336, 2007.

[26] P. E. Sottas, N. Robinson, O. Rabin, and M. Saugy, "The athlete biological passport," Clinical Chemistry, vol. 57, no. 7, pp. 969976, 2011.

[27] G. Banfi, "Reticulocytes in sports medicine," Sports Medicine, vol. 38, no. 3, pp. 187-211, 2008.

[28] V. S. Nadarajan, C. H. Ooi, P. Sthaneshwar, and M. W. Thompson, "The utility of immature reticulocyte fraction as an indicator of erythropoietic response to altitude training in elite cyclists," International Journal of Laboratory Hematology, vol. 32, no. 1, pp. 82-87, 2010.

[29] R. Milic, J. Martinovic, M. Dopsaj, and V. Dopsaj, "Haematological and iron-related parameters in male and female athletes according to different metabolic energy demands," European Journal of Applied Physiology, vol. 111, no. 3, pp. 449-458, 2011.

[30] G. Banfi, C. Lundby, P. Robach, and G. Lippi, "Seasonal variations of haematological parameters in athletes," European Journal of Applied Physiology, vol. 111, no. 1, pp. 9-16, 2011.

[31] N. Mathur and B. K. Pedersen, "Exercise as a mean to control low-grade systemic inflammation," Mediators of Inflammation, vol. 2008, Article ID 109502, 6 pages, 2008.

[32] E. J. Erlandsen and E. Randers, "Reference interval for serum C-reactive protein in healthy blood donors using the Dade Behring N Latex CRP mono assay," Scandinavian Journal of Clinical and Laboratory Investigation, vol. 60, no. 1, pp. 37-44, 2000.

[33] T. B. Ledue and N. Rifai, "Preanalytic and analytic sources of variations in C-reactive protein measurement: implications for cardiovascular disease risk assessment," Clinical Chemistry, vol. 49, no. 8, pp. 1258-1271, 2003.

[34] P. M. Ridker, "Clinical application of C-reactive protein for cardiovascular disease detection and prevention," Circulation, vol. 107, no. 3, pp. 363-369, 2003.

[35] K. E. Fallon, "The clinical utility of screening of biochemical parameters in elite athletes: analysis of 100 cases," British Journal of Sports Medicine, vol. 42, no. 5, pp. 334-337, 2008.

[36] P. Peeling, B. Dawson, C. Goodman, G. Landers, and D. Trinder, "Athletic induced iron deficiency: new insights into the role of inflammation, cytokines and hormones," European Journal of Applied Physiology, vol. 103, no. 4, pp. 381-391, 2008.

[37] N. C. Andrews and P. J. Schmidt, "Iron homeostasis," Annual Review of Physiology, vol. 69, pp. 69-85, 2007.
[38] P. Peeling, B. Dawson, C. Goodman et al., "Effects of exercise on hepcidin response and iron metabolism during recovery," International Journal of Sport Nutrition and Exercise Metabolism, vol. 19, no. 6, pp. 583-597, 2009.

[39] E. H. J. M. Kemna, H. Tjalsma, H. L. Willems, and D. W. Swinkels, "Hepcidin: from discovery to differential diagnosis," Haematologica, vol. 93, no. 1, pp. 90-97, 2008.

[40] E. Nemeth, S. Rivera, V. Gabayan et al., "IL-6 mediates hypoferremia of inflammation by inducing the synthesis of the iron regulatory hormone hepcidin," The Journal of Clinical Investigation, vol. 113, no. 9, pp. 1271-1276, 2004.

[41] E. Kemna, P. Pickkers, E. Nemeth, H. Van Der Hoeven, and D. Swinkels, "Time-course analysis of hepcidin, serum iron, and plasma cytokine levels in humans injected with LPS," Blood, vol. 106, no. 5, pp. 1864-1866, 2005.

[42] W. Jelkmann, "Regulation of erythropoietin production," The Journal of Physiology, vol. 589, no. 6, pp. 1251-1258, 2011.

[43] C. Thomas and L. Thomas, "Biochemical markers and hematologic indices in the diagnosis of functional iron deficiency," Clinical Chemistry, vol. 48, no. 7, pp. 1066-1076, 2002.

[44] L. Thomas, S. Franck, M. Messinger, J. Linssen, M. Thomé, and C. Thomas, "Reticulocyte hemoglobin measurementcomparison of two methods in the diagnosis of iron-restricted erythropoiesis," Clinical Chemistry and Laboratory Medicine, vol. 43, no. 11, pp. 1193-1202, 2005.

[45] S. Recalcati, P. Invernizzi, P. Arosio, and G. Cairo, "New functions for an iron storage protein: the role of ferritin in immunity and autoimmunity," Journal of Autoimmunity, vol. 30, no. 1-2, pp. 84-89, 2008. 

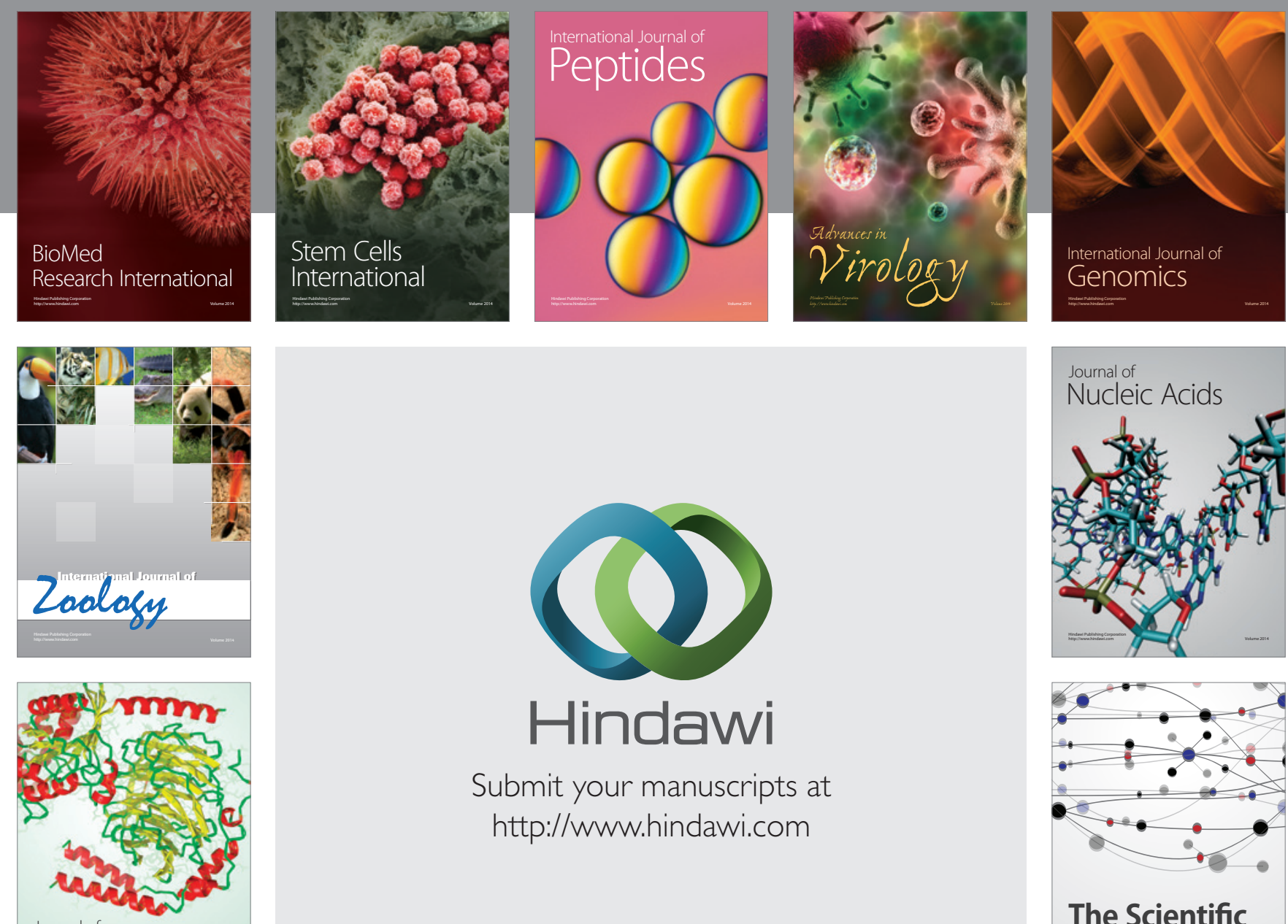

Submit your manuscripts at

http://www.hindawi.com

Journal of
Signal Transduction
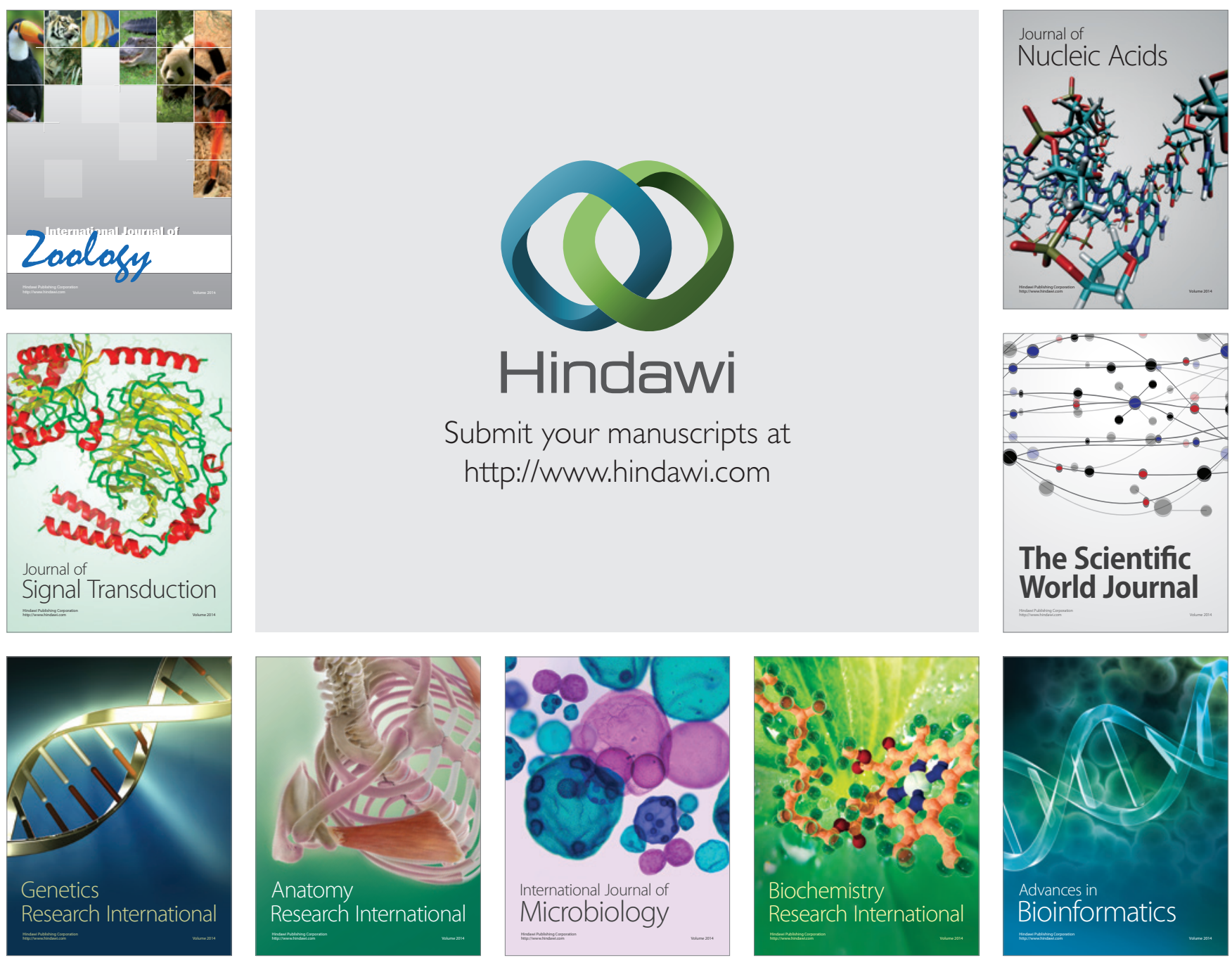

The Scientific World Journal
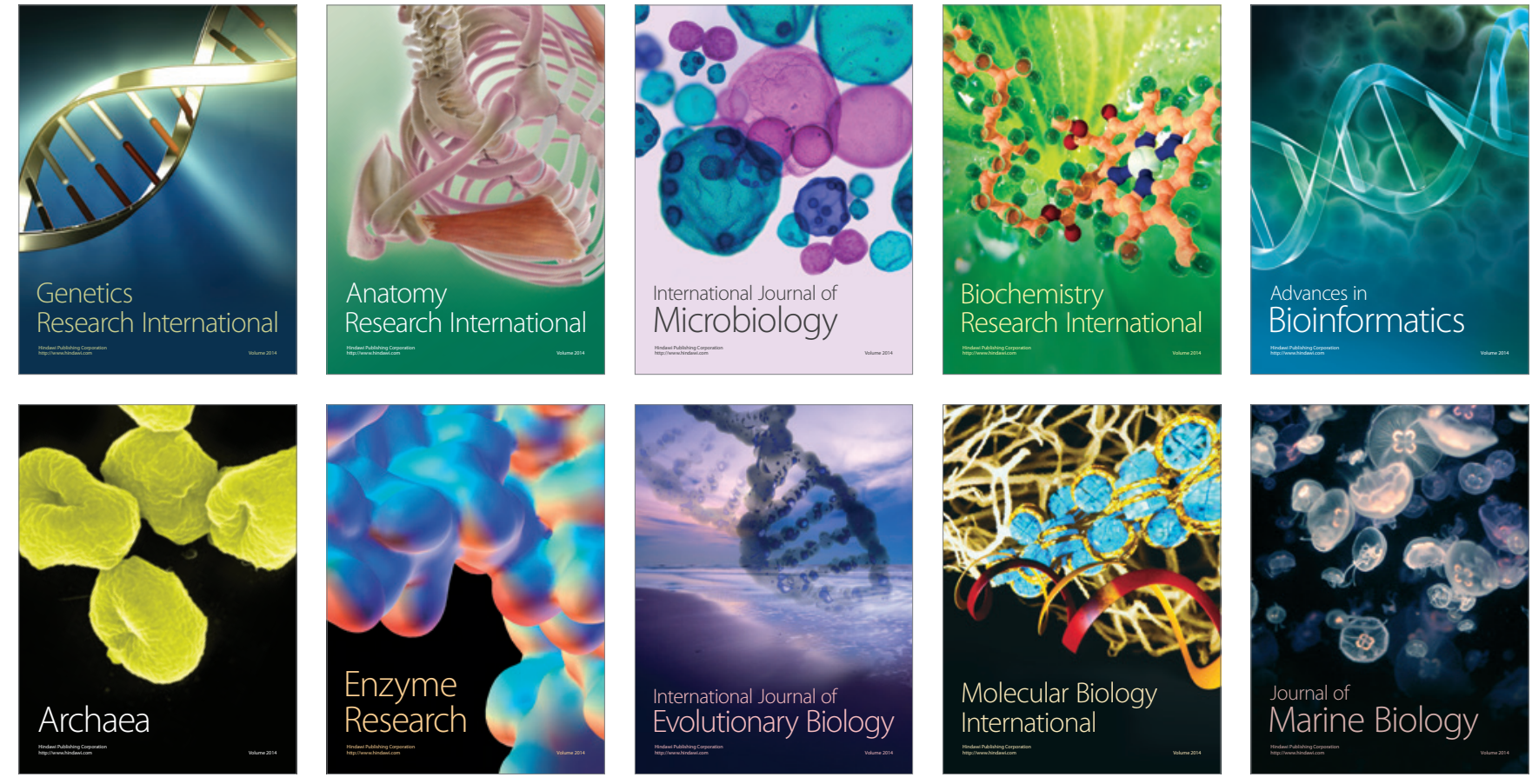